\title{
Influence of polycyclic aromatic hydrocarbon exposure on IVF: now is the time to focus on women
}

\author{
Antoine Netter ${ }^{1,2, *}$, Elena Siri ${ }^{1,2}$, Virginie Tassitro ${ }^{2}$, Noémie Resseguier ${ }^{3}$, \\ Nicolas Beauval ${ }^{4}$, Irène Sari-Minodier ${ }^{2,5}$, Blandine Courbiere ${ }^{1,2}$, \\ Jeanne Perrin ${ }^{2,6}$
}

\begin{abstract}
Research question: Is polycyclic aromatic hydrocarbon (PAH) exposure associated with the reproductive outcomes of IVF treatment?
\end{abstract}

Design: A prospective, small-scale monocentric cohort study of couples who underwent IVF treatment between January 2018 and June 2019. Both members of each couple answered a questionnaire on PAH exposure and provided urine samples to measure urinary 1-hydroxypyrene (1-OHP) the day before oocyte retrieval and semen collection for fertilization. To assess the specific PAH exposure of gamete cells, immunostaining was conducted on both spermatozoa and granulosa cells obtained during IVF with an anti-benzo(a)pyrene diol epoxide (BPDE) monoclonal antibody that recognizes BDPE-DNA adducts. To assess DNA damage, a comet assay on spermatozoa was conducted. The PAH exposure was compared between couples who had positive HCG and couples who had negative HCG on day 14 after embryo transfer.

Results: Eighteen couples were included. The mean 1-OHP level in women whose HCG tests were positive $(n=6)$ was significantly lower than that in women with negative HCG tests (0.098 [0.042-0.170] versus 0.177 [0.067-0.812] $\mu \mathrm{g} / \mathrm{g}$ creatinine; $P=0.048$ ). The presence of BPDE-DNA adducts in granulosa cells of women with a negative (29.7 [16.2-57.5] arbitrary units) or positive HCG test (20.3 [9.3-23.3] arbitrary units) were not significantly different $(P=0.092)$. The urinary 1-OHP levels of men and BPDE-DNA adducts in spermatozoa showed no differences between groups.

Conclusions: This exploratory research should encourage further studies to determine the effect of women's exposure to PAHs on reproductive outcomes of IVF treatment.

\footnotetext{
${ }^{1}$ Department of Gynecology, Obstetrics and Reproductive Medicine, AP-HM La Conception, Pôle femmes parents enfants, 147 bd Baille, Marseille 13005, France

${ }^{2}$ Aix Marseille Univ, Avignon Université, CNRS, IRD, IMBE, Marseille, France

${ }^{3}$ Laboratoire de santé publique (EA 3279) (public health laboratory), faculté de Médecine de la Timone, 27, boulevard Jean Moulin, Marseille cedex 5 13385, France

${ }^{4} \mathrm{CHU}$ Lille, Unité Fonctionnelle de Toxicologie, Lille F-59000, France

${ }^{5}$ Service hospitalo-universitaire de médecine et santé au travail, Faculté des Sciences Médicales et Paramédicales, AP-HM

La Timone, Aix Marseille Univ 27, boulevard Jean Moulin, Marseille Cedex 5 13385, France

${ }^{6}$ Laboratoire de Biologie de la Reproduction - CECOS, Pole Femmes-Parents-Enfants, AP-HM La Conception, Marseille, France
}

\section{KEYWORDS}

Biomarkers

Comet assay

Environment

Polycyclic aromatic hydrocarbons 


\section{INTRODUCTION}

$\mathrm{P}$

olycyclic aromatic hydrocarbons

(PAH) are ubiquitous and recalcitrant pollutants produced by incomplete combustion of organic substances (Alegbeleye et al., 2017). Polluted air, occupational exposure, cigarette smoke and charbroiled or contaminated food are exposing millions of humans to PAH (Zhang et al., 2008; Liu et al., 2012). Sixteen PAH are designated priority pollutants for monitoring by the European and US environmental protection agencies for their carcinogenic and mutagenic properties (European Parliament, Council on Environmental Quality Standards in the Field of Water Policy, 2008; US Environmental Protection Agency, 2014).

Data on the effect of PAH exposure on human reproduction are scarce. The results of several studies have suggested that the exposure of men to $\mathrm{PAH}$ is associated with DNA damage in spermatozoa without interfering with semen parameters. In men, exposure to PAH might therefore be related to infertility and might not be diagnosed by a common semen analysis (Zenzes et al., 1999a; Gaspari et al., 2003; Han et al., 2011; Perrin et al., 2011; Jeng et al., 2013; Yang et al., 2017). In-vivo studies in mice have identified several mechanisms that explain how exposure to PAH could damage spermatozoa DNA (Revel et al., 2001; Inyang et al., 2003; Ramesh et al., 2004; 2008). The transformation of $\mathrm{PAH}$ into epoxide metabolites that bind covalently to DNA and induces a stable primary lesion (termed a DNA adduct) is the most unanimously accepted mechanism (Zenzes et al., 1999a; Revel et al., 2001; Baird and Ralston, 2004; Perrin et al., 2011). In addition, PAH epoxide metabolites are formed via a microsomal cytochrome P450dependent monooxygenase system that is known to increase the production of reactive oxygen species and potentially damage DNA (Park et al., 1996; Lopes et al., 1998).

Data on the effect of PAH exposure on female fertility are even more scarce. In-vivo animal studies have suggested that the PAH affect the ovarian follicles and oocyte and cumulus cell DNA through similar mechanisms than for spermatozoa (Bengtsson et al., 1983; Neal et al., 2007; Ramesh et al., 2010;
Sobinoff et al., 2012; Einaudi et al., 2014). Because of obvious difficulties obtaining human ovarian cells, to date, only one study has investigated the effect of PAH on female fertility. In 1998, Zenzes et al. (1998) revealed the formation of BPDEDNA adducts in the granulosa cells of 32 women undergoing IVF treatment who were exposed to cigarette smoke (Zenzes et al., 1998). The same team found more BPDE-DNA adducts in the embryos of smoking couples than in those of nonsmoking couples, suggesting that DNA damage caused by PAH exposure could be transmitted to the embryos. The reproductive outcomes of IVF, however, were not reported in that study (Zenzes et al., 1999a).

Over recent decades, increasing research has been conducted to identify the best practices to increase the chances of pregnancy with IVF treatment (Kushnir et al., 2017). The influence of lifestyle and environmental exposure on the outcomes of IVF have increasingly been researched (Hornstein, 2016; Vizcaíno et al., 2016; Choe et al., 2018). Despite the presumption of impairment of human gametes owing to $\mathrm{PAH}$ exposure, however, to the best of our knowledge, nothing is known on its influence on the success of assisted reproductive technology (ART) treatments.

The aim of this small-scale prospective, monocentric, cohort study was to determine whether $\mathrm{PAH}$ exposure among women and men was associated with the outcomes of IVF treatment.

\section{MATERIALS AND METHODS}

\section{Study design}

A small-scale prospective, monocentric, cohort study was conducted in our ART unit at La Conception University Hospital in Marseille, France. Data were prospectively and anonymously collected. The study was approved (20 June 2018) by the Ouest II Committee for the Protection of Research Subjects (RCB: 2018-A00364-51). Women and men from each couple provided written informed consent. The trial is registered with ClincalTrials.gov (reference: NCT03914859).

\section{Study population}

Couples who underwent IVF treatments in our ART unit were enrolled between February 2018 and June 2019. Couples were eligible for inclusion if the woman was aged between 18 and 36 years, had a regular menstrual cycle of between 27 and 33 days, had not had more than one other IVF attempt and if the man's age was between 18 and 45 years. Exclusion criteria were IVF with gamete donation, American Fertility Society revised stage III or IV (moderate or severe) endometriosis (Revised American Society for Reproductive Medicine classification of endometriosis, 1997), decreased ovarian reserve $(\mathrm{AMH}<1 \mathrm{ng} / \mathrm{ml})$, medical history likely to alter either ovarian reserve, fertilization rate or implantation, e.g. history of cancer with chemotherapy or radiotherapy for either member of the couple, uterine or ovarian surgery, and positive human immunodeficiency virus, hepatitis $C$ virus or hepatitis $B$ virus serologies for any member of the couple.

\section{Ovarian stimulation protocols and luteal phase support}

The ovarian stimulation protocols and luteal phase support used in our ART unit have been described previously (Netter et al., 2019). Briefly, either gonadotrophin releasing hormone agonist or gonadotrophin releasing hormone antagonist protocols were used. Either recombinant $\mathrm{FSH}$, recombinant FSH and recombinant $\mathrm{LH}$ or human menopausal gonadotrophin was used for ovarian stimulation. A single injection of $250 \mu \mathrm{g}$ of choriogonadotropin alpha (Ovitrelle, Merck Serono Europe Limited, UK) was used for final follicular maturation. Oral dydrogesterone (Duphaston ${ }^{\circledR}$, Mylan Medical, France) was used for luteal phase support.

\section{Polycyclic aromatic hydrocarbon} exposure questionnaires and expired carbon monoxide measurement On the morning of oocyte retrieval, both members of the couple answered a questionnaire assessing tobacco consumption and dietary, environmental and occupational exposures to $\mathrm{PAH}$. The questionnaire used in this study was strongly inspired by the questionnaire created by Gunier et al. (2006) for a study on PAH exposure. Questions on occupational exposure to PAH were added by using parts of another questionnaire created and published by our team in 2009 (De Fleurian et al., 2009). The first section of the questionnaire briefly focused on exposure the day before oocyte retrieval, and the second section extensively focused on exposure in day to day life (Supplementary Table 1). Participants were considered occupationally exposed 
to PAH if they answered 'yes' to one or more options in question B.1.3. ('In the workplace, are you exposed to...?). The participants were considered to be exposed to PAH by their diet if they declared that they ate, smoked or grilled meat or fish several times a week or every day (question B.2.1.). The participants were considered environmentally exposed to $\mathrm{PAH}$ if they answered 'yes' to any of the options in the following questions: B.1.4. ('Is your workplace located in a large city?'), B.1.5. ('Is your workplace located near the following locations...?'), B.2.4.1. ('Is your place of residence located in a large city?'), B.2.4.2. ('Is your residence located near the following locations...?'), and B.2.4.3. ('Do you use the following heating methods...?').

To counter the risk of underestimating tobacco consumption, both members of the couple underwent an expired carbon monoxide measurement on the morning of oocyte retrieval using a piCO Smokerlyzer carbon monoxide breath test monitor according to the manufacturer's instructions (Bedfont Scientific Ltd, Harrietsham, Maidstone, UK). The results are reported in parts per million (ppm).

\section{Urine samples and 1-hydroxypyrene measurement}

Both members of the couple were asked to provide urine samples at the end of the day preceding oocyte retrieval. When possible, oocyte retrievals were not carried out on Mondays so that the urine samples were always produced in the evening of a working day to better assess occupational exposure. Five milliliters of each urine sample were immediately collected to measure the creatinine concentration; then, the samples were stored at $-80^{\circ} \mathrm{C}$ and kept away from light until analysis. The 1-OHP measurements were conducted at the toxicology unit of Lille University Hospital, France. Briefly, after $\beta$-glucuronidase hydrolysis, urine samples successively underwent several solvent extraction, drying and reconstitution steps adapted from a published method (Li et al., 2005). They were then analysed by ultrahigh-performance liquid chromatography coupled with tandem mass spectrometry (Xevo TQ-XS, Waters, Guyancourt, France). The lower limit of quantification for $1-\mathrm{OHP}$ was $0.025 \mu \mathrm{g} / \mathrm{l}$, and $1-\mathrm{OHP}$ concentrations were adjusted to urinary creatinine. Samples with creatinine concentrations over 3.0 or less than 0.3 $\mathrm{g} / \mathrm{l}$, considered over-concentrated and over-diluted, respectively, were excluded (Leroyer et al., 2010).
Sperm and follicular cell collection and storage

Semen samples were collected by masturbation for IVF on the day of oocyte retrieval after a period of abstinence of 2-6 days. Semen analysis was carried out after $30 \mathrm{~min}$ of liquefaction at $37^{\circ} \mathrm{C}$, and smears were stained with Schorr staining in accordance with the current World Health Organization guidelines (WHO, 1999). Sperm morphology defects were assessed according to the method described by David et al. (1975) and modified by Jouannet et al (Jouannet et al., 1988).

Follicles were monitored by ultrasound during ovarian stimulation. On the day of oocyte retrieval, all follicles were aspirated $36 \mathrm{~h}$ after $\mathrm{HCG}$ administration using transvaginal guidance and local or general anaesthesia. Oocytes were then retrieved from the follicular fluid under microscope examination.

Informed consent was obtained for inclusion of the remaining sperm cells and the granulosa cells remaining in follicular fluid in the Germetheque Biobank, France, after freezing in liquid nitrogen (Di Santo et al., 2012).

Comet assay and immunostaining for anti-benzo(a)pyrene diol epoxide DNA adducts

After thawing, spermatozoa were selected by a swim-up technique already described by our team (Perrin et al., 2011). Alkaline comet assay was carried out according to the procedure described by Singh et al. (1988) and adapted by Baumgartner (2009) for human spermatozoa, which has already been described in other works by our team (Préaubert et al., 2018). The percentage of DNA in the tail and the olive tail moment of 100 randomly selected sperm cells from each slide (in triplicate per patient) was reported.

After thawing, the immunostaining and BPDE-DNA adduct quantification procedures were the same for spermatozoa and granulosa cells and have been described elsewhere (Perrin et al., 2011). The method used an anti-benzo[a]pyrene diol epoxide (BPDE) monoclonal antibody that recognizes BDPE-DNA adducts. For the men, 100 spermatozoa were randomly selected for each slide in duplicate for the analysis, and 50 granulosa cells were chosen for women. The fluorescence was expressed as arbitrary units (arb. Units) of average grey value average.

\section{End-points}

The HCG serum level was measured 14 days after embryo transfer and considered positive if HCG was greater than $100 \mathrm{IU} / \mathrm{ml}$. The primary end-points were differences in markers of exposure to PAH (urinary 1-OHP, answers to questionnaires, expired carbon monoxide and BDPE-DNA adducts immunostaining in germ cells for each member of the couple) between the couples for whom the implantation occurred (positive HCG on day 14 after embryo transfer) and those for whom implantation did not occur (negative HCG at day 14 after embryo transfer). The secondary endpoints were the correlation coefficients between the markers of exposure to $\mathrm{PAH}$ and embryo quality, semen analysis and DNA damage to spermatozoa assessed by the comet assay. Embryo quality was assessed by the Plachot and Mandelbaum classification considering the number, symmetry and fragmentation of blastomeres depending on the day of development (Plachot and Mandelbaum, 1990). Top-quality embryos were those presenting four regular blastomeres on day 2 and 8, regular blastomeres on day 3 with less than 10\% fragments, and no multinucleated blastomeres (Plachot and Mandelbaum, 1990).

\section{Statistical analysis}

Data are presented as numbers and percentages for categorical variables and as means and SD for quantitative variables or as medians and minimummaximum based on their distribution.

The sample size was estimated under the following hypotheses: a minimum effect size of 1.5; a positive or negative HCG ratio of $33 \%$ based on previously published results from our ART unit (Netter et al., 2019); a bilateral alpha risk of 0.05; and a power of 0.80 . With these criteria, a sample size of 18 couples was required (Machin et al., 2009). Considering that some couples could be excluded from the analysis, the sample size was increased, and 22 couples were recruited. First, two groups were determined based on the results of HCG on day 14 after embryo transfer. Clinical and biological characteristics were compared between these two groups. Quantitative data were compared using Student's t-tests when applicable and using Mann-Whitney 
$U$-tests otherwise. The normality of the distribution of quantitative data was checked by Levene's test. Categorical data were compared using chi-squared test when applicable and Fisher's test otherwise.

Second, correlations were examined between the markers of exposure to $\mathrm{PAH}$ and the quality of the highest-grade embryo transferred, semen analysis, and DNA damage to spermatozoa assessed by the comet assay. Results are reported as Spearman rank correlation coefficients.

All tests were two-sided, and results were considered to be significant when $P<$ 0.05. IBM SPSS Statistics 20.0 (IBM Inc., New York, USA) was used for all statistical analyses.

\section{RESULTS}

\section{Study population and reproductive} outcomes

During the study period, 22 couples undergoing IVF treatment at our ART unit were included in the study. Four couples did not have embryo transfer on day 2 after oocyte retrieval (three for ovarian hyperstimulation syndrome and one for failure to obtain embryos of sufficient quality) and were excluded from the final analysis. Among the 18 remaining couples, six $(33 \%)$ had positive HCG, and 12 (67\%) had negative HCG on day 14 after embryo transfer. Characteristics of women and embryological outcomes are presented in TABLE 1. Characteristics of men and semen parameters are presented in TABLE 2.

\section{Association between women's} polycyclic aromatic hydrocarbon exposure and reproductive outcomes and embryo quality

A comparison of women's PAH exposure between positive and negative HCG groups is presented in TABLE 3. Women who had negative HCG on day 14 after embryo transfer had significantly higher median urinary 1-OHP (0.177 [0.067-0.812] $\mu \mathrm{g} / \mathrm{g}$ creatinine) compared with women who had positive HCG (0.098 [0.042-0.170] $\mu \mathrm{g} / \mathrm{g}$ creatinine; $P=0.048$ ). The presence of BPDE-DNA adducts in granulosa cells of women with a negative HCG test (29.7 [16.2-57.5] arbitrary units) compared with women with a positive HCG test (20.3 [9.323.3] arbitrary units) were not significantly different $(P=0.092)$. Occupational, environmental and dietary exposures to PAH were similar in both groups.

The correlations between women's PAH exposure markers and the quality of

TABLE 1 WOMEN'S CHARACTERISTICS AND EMBRYOLOGICAL OUTCOMES ACCORDING TO HCG TEST RESULT ON DAY 14 AFTER EMBRYO TRANSFER

\begin{tabular}{|c|c|c|c|}
\hline Characteristics & $\mathbf{n}$ & Positive HCG & Negative HCG \\
\hline Patients, $\mathrm{n}$ & 18 & 6 & 12 \\
\hline Maternal age, years & 18 & $32 \pm 4$ & $33 \pm 3$ \\
\hline Maternal BMI, kg/m² & 18 & $23.4 \pm 3.5$ & $24.5 \pm 4.3$ \\
\hline Basal AMH, IU & & $2.2(1.5-5.14)$ & $2.0(0.8-6.7)$ \\
\hline Primary diagnosis for infertility & 18 & & \\
\hline Unexplained, n (\%) & & $2(33)$ & $5(42)$ \\
\hline Tubal, n (\%) & & $3(50)$ & $4(33)$ \\
\hline Endometriosis, n (\%) & & $0(0)$ & $0(0)$ \\
\hline PCO/PCOS, n (\%) & & $0(0)$ & $1(8)$ \\
\hline Male, n (\%) & & $1(17)$ & $2(17)$ \\
\hline mature oocytes retrieved, $\mathrm{n}$ & 18 & $11(7-25)$ & $8(3-18)$ \\
\hline Fertilization rate, $\%$ & 18 & $84(67-100)$ & $67(25-100)$ \\
\hline Number of embryos transferred, $\mathrm{n}$ & 18 & $1.3 \pm .5$ & $1.8 \pm .4$ \\
\hline $\begin{array}{l}\text { At least one top quality embryo transferred, } \\
n(\%)\end{array}$ & 18 & $5(83)$ & $4(33)$ \\
\hline Frozen embryos, $n$ & 18 & $2.5(0-9)$ & $0(0-4)$ \\
\hline Maternal smoking, n (\%) & 18 & $0(0 \%)$ & $4(33 \%)$ \\
\hline Expired carbon monoxide, ppm & 18 & $2(2-10)$ & $2.5(1-8)$ \\
\hline
\end{tabular}

Descriptive data are presented as mean \pm SD for quantitative data, or as median (minimum-maximum), according to their distribution. Categorical data are presented as numbers (\%)

$\mathrm{AMH}$, anti-Müllerian hormone; $\mathrm{PCO}$, polycystic ovaries; PCOS, polycystic ovary syndrome.

the highest-grade embryo transferred are presented in FIGURE 1. Women's urinary 1-OHP was significantly positively correlated to the degree of fragmentation of the highest-grade embryo transferred (Spearman's rho $r=0.489, P=0.040$ ).

The correlation between the BPDE-DNA adducts in granulosa cells and the degree of fragmentation of the highest-grade embryo transferred was not significant ( $r=0.290, P=0.416)$. No correlation was found between either the women's urinary 1-OHP or the BDPE-DNA adduct and the embryo score of the highestgrade embryo transferred or the chances for the highest-grade embryo transferred to be a top-quality embryo. Smoking status was strongly negatively correlated with the chances for the highest-grade embryo transferred to be a top-quality embryo ( $r=-0.535, P=0.022)$. Expired carbon monoxide did not show any correlation with any of the criteria of embryo quality.

Association between men's polycyclic aromatic hydrocarbons exposure and reproductive outcome and embryo quality

Comparisons of men's characteristics between positive and negative HCG groups are presented in TABLE 4. Occupational exposure to PAH was significantly more frequent in the negative HCG group (50\%) than in the positive HCG group ( $0 \%$; $P=0.034$ ). Nevertheless, neither the men's urinary 1-OHP nor the BDPE-DNA adducts in spermatozoa were different between groups $(P=0.562$ and $P=0.385$, respectively). Sperm DNA damage assessed by the comet assay was not significantly different between groups. Dietary and environmental exposure to PAH were similar between groups.

The correlations among men's PAH exposure markers and semen quality and sperm DNA damage assessed by the comet assay are presented in FIGURE 2. Men's urinary 1-OHP levels were not correlated with either semen parameters or sperm DNA damage. The correlation between sperm BPDE-DNA adducts and sperm DNA fragmentation parameters was not significant $(r=0.335$; $P=0.174$ for the percentage tail DNA and $r=0.337$; $P=0.123$ for the olive tail moment).

The correlations among men's PAH exposure markers and embryo quality parameters are presented in FIGURE 3 . Men's 
TABLE 2 COMPARISON OF MEN'S CHARACTERISTICS AND SEMEN PARAMETERS ACCORDING TO HCG TESTING ON DAY 14 AFTER EMBRYO TRANSFER

\begin{tabular}{llll}
\hline Characteristics & $\mathbf{n}$ & Positive HCG & Negative HCG \\
\hline Patients, $\mathrm{n}$ & 18 & 6 & 12 \\
\hline Paternal age, years & 18 & $33 \pm 4$ & $36 \pm 5$ \\
\hline Paternal BMI, kg/m² & 18 & $24.7 \pm 3.3$ & $26.1 \pm 1.9$ \\
\hline Semen volume, $\mathrm{ml}$ & 18 & $3.3(.9-4.5)$ & $3.4(2.2-5.8)$ \\
\hline Sperm concentration, G/ml & 18 & $35.6(5.9-99.5)$ & $75.0(6.1-284)$ \\
\hline Sperm motility, \% & 18 & $37.5(30-55)$ & $30(20-55)$ \\
\hline Sperm vitality, \% & 17 & $68(64-82)$ & $77(54-88)$ \\
\hline Sperm normal morphology, \% & 17 & $19(2-26)$ & $29(8-44)$ \\
\hline Paternal smoking, $\mathrm{n}$ (\%) & 18 & $3(50)$ & $3(25)$ \\
\hline Carbon monoxide breath test (ppm) & 18 & $5(2-11)$ & $3(1-11)$ \\
\hline
\end{tabular}

Descriptive data are presented as mean \pm SD for quantitative data, or as median (minimum-maximum), according to their distribution. Categorical data are presented as numbers (\%)

TABLE 3 COMPARISON OF WOMEN'S POLYCYCLIC AROMATIC HYDROCARBON EXPOSURE ACCORDING TO HCG TESTING ON DAY 14 AFTER EMBRYO TRANSFER

\begin{tabular}{|c|c|c|c|c|}
\hline Characteristics & $\mathbf{n}$ & Positive HCG & Negative HCG & $P$-value \\
\hline Patients, n & 18 & 6 & 12 & \\
\hline Occupational PAH exposure, n (\%) & 18 & $0(0)$ & $0(0)$ & 1.0 \\
\hline Dietary PAH exposure, $n(\%)$ & 18 & $3(50)$ & $5(42)$ & 0.737 \\
\hline Environmental PAH exposure, n (\%) & 18 & $4(67)$ & $5(42)$ & 0.317 \\
\hline Urinary 1-OHP ( $\mu \mathrm{g} / \mathrm{g}$ creatinine) & 18 & $0.098(0.042-0.170)$ & $0.177(0.067-0.812)$ & $0.048^{a}$ \\
\hline $\begin{array}{l}\text { Granulosa cell BPDE-DNA adducts } \\
\text { (arbitrary unit) }\end{array}$ & 10 & $20.3(9.3-23.3)$ & $29.7(16.2-57.5)$ & 0.092 \\
\hline
\end{tabular}

\begin{tabular}{|c|c|c|c|}
\hline Urinary 1-OHP & $.489 *$ & .131 & -.225 \\
\hline $\begin{array}{l}\text { BPDE-DNA } \\
\text { Adducts }\end{array}$ & .290 & .227 & -.142 \\
\hline Smoking status & -.049 & .383 & $-.535^{*}$ \\
\hline \multirow[t]{2}{*}{ CO Breath test } & .051 & .114 & .072 \\
\hline & 总 & 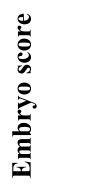 & 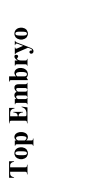 \\
\hline
\end{tabular}

urinary 1-OHP did not correlate with any of the parameters of embryo quality. The correlation between spermatozoa BPDEDNA adducts and embryo fragmentation was not significant $(r=0.386 ; P=0.114)$. No correlation was found between sperm BPDE-DNA adducts and the embryo score of the highest-grade embryo transferred or with the chances for this embryo to be a top-quality embryo. Neither tobacco consumption nor expired carbon monoxide were correlated with any of the parameters used to assess embryo quality.

\section{DISCUSSION}

To the best of our knowledge, this smallscale study is the first study to investigate the association between PAH exposure and the reproductive outcomes of IVF treatment. The urinary 1-OHP levels in women were positively correlated with fragmentation of the highest- grade embryo transferred and were significantly higher in women with a negative HCG test result 14 days after embryo transfer compared with women with a positive result. This finding suggests an association between PAH exposure in women and reduced quality of the highest-grade embryo transferred conceivably linked to the absence of implantation. The women's tobacco consumption had a negative effect on the quality of the highest-grade embryo transferred, but this effect was not mediated through the fragmentation of

\begin{tabular}{|l|l|}
\hline P-Value & Color \\
\hline$>.75$ & \\
\hline $.50-.75$ & \\
\hline $.25-.50$ & \\
\hline $.1-.25$ & \\
\hline $.05-.1$ & \\
\hline $.02-.05$ & \\
\hline $.01-.02$ & \\
\hline
\end{tabular}

FIGURE 1 Correlations between the women's exposure markers and the quality criteria of the highest-grade embryo transferred. The values in the figure show the Spearman's correlation coefficient estimates (rho) with their $P$-values indicated by colour. Embryo fragmentation is the fragmentation of the highest-grade embryo transferred assessed with a discrete variable with four possible ranges $(<10 \%, 10-30 \%, 30-50 \%$ and $>50 \%$ ). Embryo score is the score of the highest-grade embryo transferred assessed by the Plachot and Mendelbaum classification from 1 (best quality) to 4 (worst quality). Top embryo is the chances for the highest-grade embryo transferred to be a top-quality embryo (binary variable). aP $<0.05$. BPDE, benzo(a)pyrene diol epoxide; $1-\mathrm{OHP}=1$-hydroxypyrene. 
TABLE 4 COMPARISON OF MEN'S POLYCYCLIC AROMATIC HYDROCARBON EXPOSURE AND SPERM DNA DAMAGE ACCORDING TO HCG TESTING ON DAY 14 AFTER EMBRYO TRANSFER

\begin{tabular}{|c|c|c|c|c|}
\hline Characteristics & $\mathbf{n}$ & Positive HCG & Negative HCG & $P$-value \\
\hline Patients, $n$ & 18 & 6 & 12 & \\
\hline Occupational PAH exposure, n (\%) & 18 & $0(0)$ & $6(50)$ & $0.034^{a}$ \\
\hline Dietary PAH exposure, $n(\%)$ & 18 & $4(67)$ & $6(50)$ & 0.502 \\
\hline Environmental PAH exposure, n (\%) & 18 & $2(33)$ & $6(50)$ & 0.502 \\
\hline Men's urinary 1-OHP ( $\mu \mathrm{g} / \mathrm{g}$ creatinine) & 18 & $0.147(0.053-0.259)$ & $0.134(0.058-0.284)$ & 0.562 \\
\hline $\begin{array}{l}\text { Spermatozoa BPDE-DNA adducts } \\
\text { (arbitrary unit) }\end{array}$ & 18 & $15.1(10.1-32.0)$ & $13.4(6.0-28.5)$ & 0.385 \\
\hline Comet assay & 18 & & & \\
\hline Sperm tail DNA (\%) & & $38.1(22.6-50.1)$ & $28.4(21.5-49.8)$ & 0.204 \\
\hline Olive tail moment & & $5.4(3.6-10.6)$ & $4.2(3.1-9.8)$ & 0.535 \\
\hline
\end{tabular}

a $P<0.05$.Descriptive data are presented as median (minimum-maximum). Categorical data are presented as numbers (\%).BPDE, benzo(a)pyrene diol epoxide; PAH, polycyclic aromatic hydrocarbon; 1-OHP = 1-hydroxypyrene.

embryos. Notably, although the effect of smoking on fertility has been investigated in a range of studies, these studies mostly focused on ovarian reserve, semen quality and uterine receptiveness. Therefore, the effect of tobacco consumption on the quality of embryos in IVF treatment has been minimally and inconsistently investigated (Freour et al., 2008). In contrast, our results suggest that PAH exposure in men has a reduced effect on the implantation rate than women's exposure.

In 1999, Zenzes et al. (1999b) revealed that BPDE-DNA adducts could be transmitted through gametes to human preimplantation embryos (Zenzes et al., 1999b). As the investigators found similar staining intensity in embryos from couples in which both members smoked than in embryos from couples in which only the father smoked, they concluded that the contribution of modified DNA to the embryo was mainly through the spermatozoa. As the investigators acknowledged, however, this conclusion had to be confirmed by running the same analyses on embryos from couples in which only the mother smoked to presumably show that the staining would be lower. Such couples were not recruited in their study, and no other similar study has been conducted subsequently. Therefore, since the publication of this report, it has been presumed that BPDE-DNA adducts are transmitted mostly through the spermatozoa and that women's exposure to $\mathrm{PAH}$ is less likely to alter the DNA of embryos, even though the scientific evidence was insufficient. Although our study did not investigate the immunostaining of embryos, our results suggest that an association exists between PAH exposure in women and the fragmentation and, more importantly, implantation of embryos. Therefore, we hypothesize that the assumption of a lesser importance of women in the transmission of BPDE-DNA adducts to the embryos could be erroneous. Further studies involving immunostaining of embryos should be conducted to confirm this hypothesis.

To date, research on the effect of PAH on human reproduction has almost exclusively focused on men's fertility and were mostly conducted in conditions of high exposure (either in emerging countries, heavily industrialized cities affected with significant air pollution or with occupationally exposed subjects) (Hsu et al., 2006; Xia et al., 2009; Han et al., 2011; Jeng et al., 2013; Jurewicz et al., 2013; Yang et al., 2017). This study was original in that it considered the exposure of both members of the

\begin{tabular}{|c|c|c|c|c|c|c|}
\hline $\begin{array}{l}\text { Urinary } \\
\text { 1-OHP }\end{array}$ & -.154 & -.083 & -.092 & -.027 & .116 & .212 \\
\hline $\begin{array}{l}\text { BPDE-DNA } \\
\text { Adducts }\end{array}$ & .335 & .377 & -.102 & .087 & .243 & -.046 \\
\hline $\begin{array}{l}\text { Smoking } \\
\text { status }\end{array}$ & .114 & .148 & .136 & .116 & -.251 & .159 \\
\hline Expired CO & -.062 & -.144 & -.382 & .098 & .406 & .215 \\
\hline & 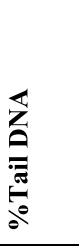 & 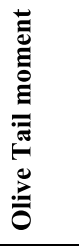 & 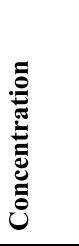 & 胥 & 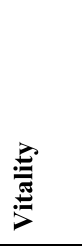 & $\begin{array}{l}\overrightarrow{0} \\
\frac{0}{0} \\
\frac{0}{2} \\
\frac{0}{2}\end{array}$ \\
\hline
\end{tabular}

\begin{tabular}{|l|l|}
\hline P-Value & Color \\
\hline$>.75$ & \\
\hline $.50-.75$ & \\
\hline $.25-.50$ & \\
\hline $.1-.25$ & \\
\hline $.05-.1$ & \\
\hline $.02-.05$ & \\
\hline $.01-.02$ & \\
\hline
\end{tabular}

FIGURE 2 Correlation of men's exposure markers with semen parameters and sperm DNA damage (assessed by the comet assay). The values in the figure show the Spearman's correlation coefficient estimates (rho) with their $P$-values indicated by colour. BPDE, benzo(a)pyrene diol epoxide; $1-\mathrm{OHP}=1$-hydroxypyrene. 


\begin{tabular}{|c|c|c|c|}
\hline 1-OHP & .103 & .044 & -.182 \\
\hline $\begin{array}{l}\text { BPDE-DNA } \\
\text { Adducts }\end{array}$ & .386 & -.214 & .225. \\
\hline $\begin{array}{l}\text { Smoking } \\
\text { status }\end{array}$ & .058 & -.229 & .0 \\
\hline Expired CO & .197 & -.007 & -.123 \\
\hline & 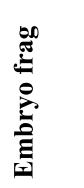 & 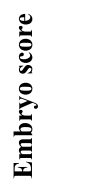 & 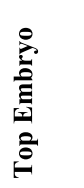 \\
\hline
\end{tabular}

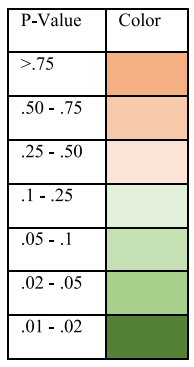

FIGURE 3 Correlations between men's exposure markers and the quality criteria of the highest-grade embryo transferred. The values in the figure show the Spearman's correlation coefficient estimates (rho) with their $P$-values indicated by colour. Embryo fragmentation is the fragmentation of the highest-grade embryo transferred assessed with a discrete variable with four possible ranges $(<10 \%, 10-30 \%, 30-50 \%$ and $>50 \%)$. Embryo score is the score of the highest-grade embryo transferred assessed by the Plachot and Mendelbaum classification from 1 (best quality) to 4 (worst quality). Top embryo is the chances for the highest-grade embryo transferred to be a top-quality embryo (binary variable).

couple and that it was conducted in a region mildly affected by $\mathrm{PAH}$ pollution. Therefore, our results are more likely to generalize to other fertility clinics in highincome countries. The underlying goal of this study, assuming that its results are confirmed by subsequent larger studies, was to ultimately determine a specific threshold for 1-OHP or other PAH metabolites above which the implantation of the embryo is unlikely to occur, thereby justifying postponement of the IVF stimulation cycle until the exposure factor is identified and eliminated. These thresholds could be different from those that are currently used for monitoring professional exposure as they were not measured to predict implantation.

The most obvious limitation of the present study was the small sample size. The low number of patients exposed (only three women and no men had urinary 1-OHP levels above $0.3 \mu \mathrm{g} / \mathrm{g}$ creatinine) did not allow us to create useful groups of exposure, and we were unable to propose a suitable and specific cut-off. We carefully selected our population only to include couples that were not exposed to other factors that would alter the chances of implantation. Our original intention was to obtain a cohort of couples for whom the absence of pregnancy could not be easily explained by any other obvious cause, e.g. advanced age, endometriosis and decreased ovarian reserve. To this end, we mostly retained couples for whom the primary diagnosis was either unexplained or tubal infertility. Although this rigorous method adds reliability to our results, it also dramatically prolonged the study period to almost 18 months to include the required number of couples. The lesson to be learned from this small-scale study is that further research on the matter should be conducted in collaboration with other ART units to include enough patients in a reasonable amount of time. The interpretation of our results is also limited by a possible confounding bias as the sample size and the data available were insufficient to conduct a reliable logistic regression analysis. In particular, it is impossible to rule out the influence of other pollutants as co-exposures are common. Indeed, the PAH exposure could be associated with the exposure to other substances that could negatively influence the reproductive outcomes on their own or in synergy with the PAH. To overcome this bias in further studies, other biomarkers should also be measured.

Another limitation to this study was that we only measured one PAH urinary metabolite. Although 1-OHP is the most commonly used urinary biomarker for estimating exposure to $\mathrm{PAH}$, most of the studies on the matter rely on various sets of PAH metabolites to obtain a more accurate representation of different parent compounds (Castano-Vinyals et al., 2004; Han et al., 2011). Further studies on the effect of PAH on IVF should be conducted with a larger set of urinary metabolites and with repeated measurements over time to assess the exposure more accurately.

In conclusion, although this exploratory research should be interpreted with caution, it should encourage further studies to determine the effect of PAH exposure of couples and of the exposure of women on reproductive outcomes of IVF treatment, in particular.

\section{ACKNOWLEDGEMENTS}

The authors would like to thank Dr Claire Sunyach and all the people involved in the Couple Reproduction Environnement et Risque (CREER) platform for their contribution to the organization of the present study. This work was financially supported by the French Biomedecine Agency (Agence de la biomédecine). 


\section{REFERENCES}

Alegbeleye, O.O., Opeolu, B.O., Jackson, V.A. Polycyclic Aromatic Hydrocarbons: A Critical Review of Environmental Occurrence and Bioremediation. Environ Manage 2017; 60: 758-783. doi:10.1007/s00267-017-0896-2

Baird, WM, Ralston, SL Carcinogenic polycyclic aromatic hydrocarbons. Bowden G.T., Fischer S. Comprehensive Toxicology Chemical Carcinogens and Anticarcinogens 2004: 171-200

Baumgartner, A., Cemeli, E., Anderson, D. The comet assay in male reproductive toxicology. Cell Biol. Toxicol. 2009; 25: 81-98. doi:10.1007/ s10565-007-9041-y

Bengtsson, M., Montelius, J., Mankowitz, L. Rydström, J. Metabolism of polycyclic aromatic hydrocarbons in the rat ovary. Comparison with metabolism in adrenal and liver tissues. Biochem. Pharmacol. 1983; 32: 129-136

Castano-Vinyals, G., D'Errico, A., Malats, N., Kogevinas, M. Biomarkers of exposure to polycyclic aromatic hydrocarbons from environmental air pollution. Occup Environ Med 2004; 61: e12. doi:10.1136/ oem.2003.008375

Choe, S.A., Jun, Y.B., Lee, W.S., Yoon, T.K., Kim, S.Y. Association between ambient air pollution and pregnancy rate in women who underwent IVF. Hum. Reprod. 2018; 33: 1071-1078. doi:10.1093/humrep/dey076

David, G., Bisson, J.P., Czyglik, F. Anomalies morphologiques du spermatozoïde humain. Propositions pour un système de classification. J Gynecol Obstet Biol Reprod (Paris) 1975; 4: 17-36

De Fleurian, G., Perrin, J., Ecochard, R., Dantony, E., Lanteaume, A., Achard, V., Grillo, J.-M., Guichaoua, M.-R., Botta, A., Sari-Minodier, I. Occupational exposures obtained by questionnaire in clinical practice and their association with semen quality. J. Androl. 2009; 30: 566-579. doi:10.2164/ jandrol.108.005918

Di Santo, M., Tarozzi, N., Nadalini, M., Borini, A. Human Sperm Cryopreservation: Update on Techniques, Effect on DNA Integrity, and Implications for ART. Adv Urol 2012854837. doi:10.1155/2012/854837

Einaudi, L., Courbiere, B., Tassistro, V., Prevot, C., Sari-Minodier, I., Orsiere, T., Perrin, J. In vivo exposure to benzo(a)pyrene induces significant DNA damage in mouse oocytes and cumulus cells. Hum. Reprod. 2014; 29: 548-554. doi:10.1093/humrep/det439

European Parliament, Council on Environmental Quality Standards in the Field of Water Policy., 2008. Directive 2008/105/EC.

Freour, T., Masson, D., Mirallie, S., Jean, M., Bach, K., Dejoie, T., Barriere, P. Active smoking compromises IVF outcome and affects ovarian reserve. Reprod. Biomed. Online 2008; 16 : 96-102. doi:10.1016/s1472-6483(10)60561-5

Gaspari, L., Chang, S.S., Santella, R.M., Garte, S., Pedotti, P., Taioli, E. Polycyclic aromatic hydrocarbon-DNA adducts in human sperm as a marker of DNA damage and infertility. Mutat. Res. 2003; 535: 155-160

Gunier, R.B., Reynolds, P., Hurley, S.E., Yerabati, S., Hertz, A., Strickland, P., Horn-Ross, P.L. Estimating exposure to polycyclic aromatic hydrocarbons: a comparison of survey, biological monitoring, and geographic information system-based methods. Cancer
Epidemiol. Biomarkers Prev. 2006; 15: $1376-$ 1381. doi:10.1158/1055-9965.EPI-05-0799

Han, X., Zhou, N., Cui, Z., Ma, M., Li, L., Cai, M., Li, Yafei, Lin, H., Li, Ying, Ao, L., Liu, J., Cao, J. Association between urinary polycyclic aromatic hydrocarbon metabolites and sperm DNA damage: a population study in Chongqing, China. Environ. Health Perspect 2011; 119: 652-657. doi:10.1289/ehp.1002340

Hornstein, M.D. Lifestyle and IVF Outcomes. Reprod Sci 2016; 23: 1626-1629. doi:10.1177/1933719116667226

Hsu, P.-C., Chen, I.-Y., Pan, C.-H., Wu, K.-Y., Pan, M.H., Chen, J.-R., Chen, C.-J., Chang-Chien, G.-P., Hsu, C.-H., Liu, C.-S., Wu, M.-T. Sperm DNA damage correlates with polycyclic aromatic hydrocarbons biomarker in coke-oven workers. Int Arch Occup Environ Health 2006; 79: 349-356. doi:10.1007/s00420-005-0066-3

Inyang, F., Ramesh, A., Kopsombut, P., Niaz, M.S., Hood, D.B., Nyanda, A.M., Archibong, A.E. Disruption of testicular steroidogenesis and epididymal function by inhaled benzo(a) pyrene. Reproductive Toxicology 2003; 17: 527-537. doi:10.1016/S0890-6238(03)00071-6

Jeng, H.A., Pan, C.-H., Chao, M.-R.

1-Hydroxypyrene as a biomarker for assessing the effects of exposure to polycyclic aromatic hydrocarbons on semen quality and sperm DNA integrity. J Environ Sci Health A Tox Hazard Subst Environ Eng 2013; 48: 152-158. doi:10.1080/03601234.2012.716741

Jouannet, P., Ducot, B., Feneux, D., Spira, A Male factors and the likelihood of pregnancy in infertile couples. I. Study of sperm characteristics. Int. J. Androl. 1988; 11: 379-394. doi:10.1111/j.1365-2605.1988.tb01011.x

Jurewicz, J., Radwan, M., Sobala, W., Brzeźnicki, S., Ligocka, D., Radwan, P., Bochenek, M., Hanke, W. Association between a biomarker of exposure to polycyclic aromatic hydrocarbons and semen quality. Int J Occup Med Environ Health 2013; 26: 790-801. doi:10.2478/s13382013-0152-9

Kushnir, V.A., Barad, D.H., Albertini, D.F., Darmon, S.K., Gleicher, N. Systematic review of worldwide trends in assisted reproductive technology 2004-2013. Reprod. Biol. Endocrinol. 2017; 15: 6. doi:10.1186/s12958-016-0225-2

Leroyer, A., Jeandel, F., Maitre, A., Howsam, M., Deplanque, D., Mazzuca, M., Nisse, C. 1-Hydroxypyrene and 3-hydroxybenzo[a] pyrene as biomarkers of exposure to $\mathrm{PAH}$ in various environmental exposure situations. Sci. Total Environ. 2010; 408: 1166-1173. doi:10.1016/j.scitotenv.2009.10.073

Li, Y., Li, A.C., Shi, H., Zhou, S., Shou, W.Z., Jiang, X., Naidong, W., Lauterbach, J.H The use of chemical derivatization to enhance liquid chromatography/tandem mass spectrometric determination of 1-hydroxypyrene, a biomarker for polycyclic aromatic hydrocarbons in human urine. Rapid Commun. Mass Spectrom. 2005; 19 3331-3338. doi:10.1002/rcm.2196

Liu, L.-Y., Wang, J.-Z., Wei, G.-L., Guan, Y.-F., Zeng, E.Y. Polycyclic aromatic hydrocarbons (PAHs) in continental shelf sediment of China: implications for anthropogenic influences on coastal marine environment. Environ. Pollut. 2012; 167: 155-162. doi:10.1016/j. envpol.2012.03.038

Lopes, S., Jurisicova, A., Sun, J.G., Casper, R.F. Reactive oxygen species: potential cause for
DNA fragmentation in human spermatozoa. Hum. Reprod. 1998; 13: 896-900

Machin, D., Campbell, M., Tan, B.T., Tan, S.H. 2009 Sample Size Tables for Clinical Studies. Wiley-Blackwell

Neal, M.S., Zhu, J., Holloway, A.C., Foster, W.G Follicle growth is inhibited by benzo-[a]pyrene, at concentrations representative of human exposure, in an isolated rat follicle culture assay. Hum. Reprod. 2007; 22: 961-967. doi:10.1093/humrep/del487

Netter, A., Mancini, J., Buffat, C., Agostini, A., Perrin, J., Courbiere, B. Do early luteal serum progesterone levels predict the reproductive outcomes in IVF with oral dydrogesterone for luteal phase support?. PLoS ONE 2019; 14e0220450. doi:10.1371/journal.pone.0220450 Organisation, W.H. 1999 WHO Laboratory Manual for the Examination of Human Semen and Sperm-Cervical Mucus Interaction. Cambridge University Press

Park, J.Y., Shigenaga, M.K., Ames, B.N. Induction of cytochrome P4501A1 by 2,3,7,8-tetrachlorodibenzo-p-dioxin or indolo(3,2-b)carbazole is associated with oxidative DNA damage. Proc. Natl. Acad. Sci. U.S.A. 1996; 93: 2322-2327

Perrin, J., Tassistro, V., Mandon, M., Grillo, J.-M., Botta, A., Sari-Minodier, I. Tobacco consumption and benzo(a)pyrene-diolepoxide-DNA adducts in spermatozoa: in smokers, swim-up procedure selects spermatozoa with decreased DNA damage. Fertil. Steril. 2011; 95: 2013-2017. doi:10.1016/j fertnstert.2011.02.021

Plachot, M., Mandelbaum, J. Oocyte maturation, fertilization and embryonic growth in vitro. Br. Med. Bull. 1990; 46: 675-694. doi:10.1093/ oxfordjournals.bmb.a072424

Préaubert, L., Tassistro, V., Auffan, M., SariMinodier, I., Rose, J., Courbiere, B., Perrin, $J$. Very low concentration of cerium dioxide nanoparticles induce DNA damage, but no loss of vitality, in human spermatozoa. Toxicol In Vitro 2018; 50: 236-241. doi:10.1016/j. tiv.2018.03.013

Ramesh, A., Archibong, A.E., Niaz, M.S. Ovarian susceptibility to benzo[a]pyrene: tissue burden of metabolites and DNA adducts in F-344 rats. J. Toxicol. Environ. Health Part A 2010; 73: 1611-1625. doi:10.1080/15287394.201 0.514225

Ramesh, A., Inyang, F., Knuckles, M.E. Modulation of adult rat benzo(a)pyrene ( $\mathrm{BaP}$ ) metabolism and DNA adduct formation by neonatal diethylstilbestrol (DES) exposure. Exp. Toxicol. Pathol. 2004; 56: 129-138. doi:10.1016/j. etp.2004.08.005

Ramesh, A., Inyang, F., Lunstra, D.D., Niaz, M.S., Kopsombut, P., Jones, K.M., Hood D.B., Hills, E.R., Archibong, A.E. Alteration of fertility endpoints in adult male F-344 rats by subchronic exposure to inhaled benzo(a) pyrene. Exp. Toxicol. Pathol. 2008; 60: 269-280. doi:10.1016/j.etp.2008.02.010

Revel, A., Raanani, H., Younglai, E., Xu, J., Han, R., Savouret, J.F., Casper, R.F. Resveratrol, a natural aryl hydrocarbon receptor antagonist, protects sperm from DNA damage and apoptosis caused by benzo(a)pyrene. Reprod. Toxicol. 2001; 15: 479-486

Revised American Society for Reproductive Medicine classification of endometriosis: 1996. Fertil. Steril. 1997; 67: 817-821. doi:10.1016/s0015-0282(97)81391-x 
Singh, N.P., McCoy, M.T., Tice, R.R., Schneider, E.L. A simple technique for quantitation of low levels of DNA damage in individual cells. Exp. Cell Res. 1988; 175: 184-191. doi:10.1016/00144827(88)90265-0

Sobinoff, A.P., Pye, V., Nixon, B., Roman, S.D., McLaughlin, E.A. Jumping the gun: smoking constituent $\mathrm{BaP}$ causes premature primordial follicle activation and impairs oocyte fusibility through oxidative stress. Toxicol. Appl. Pharmacol. 2012; 260: 70-80. doi:10.1016/j. taap.2012.01.028

US Environmental Protection Agency, 2014. Priority Pollutant List.

Vizcaíno, M.A.C., González-Comadran, M., Jacquemin, B. Outdoor air pollution and human infertility: a systematic review. Fertility and Sterility 2016; 106. doi:10.1016/j. fertnstert.2016.07.1110
Xia, Y., Zhu, P., Han, Y., Lu, C., Wang, S., Gu, A., Fu, G., Zhao, R., Song, L., Wang, X. Urinary metabolites of polycyclic aromatic hydrocarbons in relation to idiopathic male infertility. Hum. Reprod. 2009; 24: 1067-1074. doi:10.1093/humrep/dep006

Yang, P., Wang, Y.-X., Sun, L., Chen, Y.-J., Liu, C., Huang, L.-L., Lu, W.-Q., Zeng, Q. Urinary metabolites of polycyclic aromatic hydrocarbons, sperm DNA damage and spermatozoa apoptosis. J. Hazard. Mater. 2017; 329: 241-248. doi:10.1016/j.jhazmat.2017.01.053

Zenzes, M.T., Bielecki, R., Reed, T.E. Detection of benzo(a)pyrene diol epoxide-DNA adducts in sperm of men exposed to cigarette smoke. Fertil. Steril. 1999; 72: 330-335

Zenzes, M.T., Puy, L.A., Bielecki, R. Immunodetection of benzo[a]pyrene adducts in ovarian cells of women exposed to cigarette smoke. Mol. Hum. Reprod. 1998 4: 159-165

Zenzes, M.T., Puy, L.A., Bielecki, R., Reed, T.E. Detection of benzo[a]pyrene diol epoxideDNA adducts in embryos from smoking couples: evidence for transmission by spermatozoa. Mol. Hum. Reprod. 1999; 5 125-131

Zhang, W., Zhang, S., Wan, C., Yue, D., Ye, Y., Wang, X. Source diagnostics of polycyclic aromatic hydrocarbons in urban road runoff, dust, rain and canopy throughfall. Environ. Pollut. 2008; 153: 594-601. doi:10.1016/j envpol.2007.09.004 